\title{
Crystal structure determination of three polycyclic compounds and comparative Rietveld refinement between MS and GSAS programs
}

\author{
WU XiaoQing, TANG PeiXiao, PAN QingQing, CHENG Qiang \& LI Hui* \\ College of Chemical Engineering, Sichuan University, Chengdu 610065, China
}

Received January 15, 2013; accepted February 28, 2013; published online April 28, 2013

The crystal structures of normethisterone, gestonoronacetat, and griseofulvin were directly determined from the X-ray powder diffraction (XRPD) using the direct space approach by means of material studio (MS), the Rietveld refinement (RR), based on MS and generalized structural analysis system (GSAS) programs, was examined to practice and expand the Rietveld (whole-profile) technique in the pharmaceutical field. The RR converges to $R_{\mathrm{wp}}=8.85 \%, 10.56 \%$, and $5.92 \%$ for normethisterone $(6.88 \%)$, gestonoronacetat $(9.58 \%)$, and griseofulvin $(5.24 \%)$, respectively. The crystallographic data obtained from the powder diffraction data were compared with the single-crystal X-ray diffraction (SXRD) data. The results showed that the maximum relative errors of lengths $a, b$, and $c$ and volume were respectively $0.18 \%, 0.18 \%, 0.22 \%$, and $0.39 \%$ between SXRD and XRPD. Thus, MS and GSAS programs were useful to powder diffractionists in determining the crystal structure of organic polycyclic molecules.

normethisterone, gestonoronacetat, griseofulvin, X-ray powder diffraction, single-crystal X-ray diffraction, Rietveld refinement

Citation: Wu X Q, Tang P X, Pan Q Q, et al. Crystal structure determination of three polycyclic compounds and comparative Rietveld refinement between MS and GSAS programs. Chin Sci Bull, 2013, 58: 2430-2434, doi: 10.1007/s11434-013-5837-8

X-ray powder diffraction (XRPD) has become one of the most popular testing methods in the crystallography since 1990 [1]. Several studies would have failed without the utilization of remarkable computer advancements. Smith and Gorter [2] identified over 280 programs for the analysis of powder diffraction data. Only some programs such as material studio (MS) can independently complete the whole process of structure determination. We previously successfully solved the crystal structures of 7-ADCA [3], jatrorrhizine chloride [4], $\beta$-cyclodextrin- $p$-aminobenzoic acid inclusion complex [5], and others by XRPD in MS 4.0. Nevertheless, Rietveld refinement (RR) [6] using non-linear least-square fitting from Reflex Plus in MS 4.0 is a rather rough tool in refining all variables together. Moreover, some molecule restraints cannot be performed well.

To date, generalized structural analysis system (GSAS) [7], FULLPROF [8] and TOPAS [9] have the widest usage

*Corresponding author (email: lihuilab@sina.com) for RR. The Argonne National Laboratory indicated that $75 \%$ of users select GSAS. GSAS supports all types of crystallography instruments, and has special features not found in most packages. However, RR in GSAS is mostly used in the inorganic field, and only a few cases like structure determination of the inclusion complex of $\beta$-cyclodextrin with lipoic acid [10] are reported.

Considering the above situations, we attempt to use RR in the GSAS program for three polycyclic rigid compounds, namely, normethisterone $\left(\mathrm{C}_{19} \mathrm{H}_{28} \mathrm{O}_{2}\right)$ as the progestogen drug, gestonoronacetat $\left(\mathrm{C}_{22} \mathrm{H}_{30} \mathrm{O}_{4}\right)$ as the intermediate of hormone medicines and griseofulvin $\left(\mathrm{C}_{17} \mathrm{H}_{17} \mathrm{ClO}_{6}\right)$ for ringworm therapy (Figure 1(a)-(c)). To date, the crystal structures of normethisterone and gestonoronacetat have not been determined from XRPD or single-crystal X-ray diffraction (SXRD). The single crystallographic data of griseofulvin are from the Cambridge Structural Database with the reference code GRISFL03, and the raw powder diffraction data are based on our laboratory work [11]. 


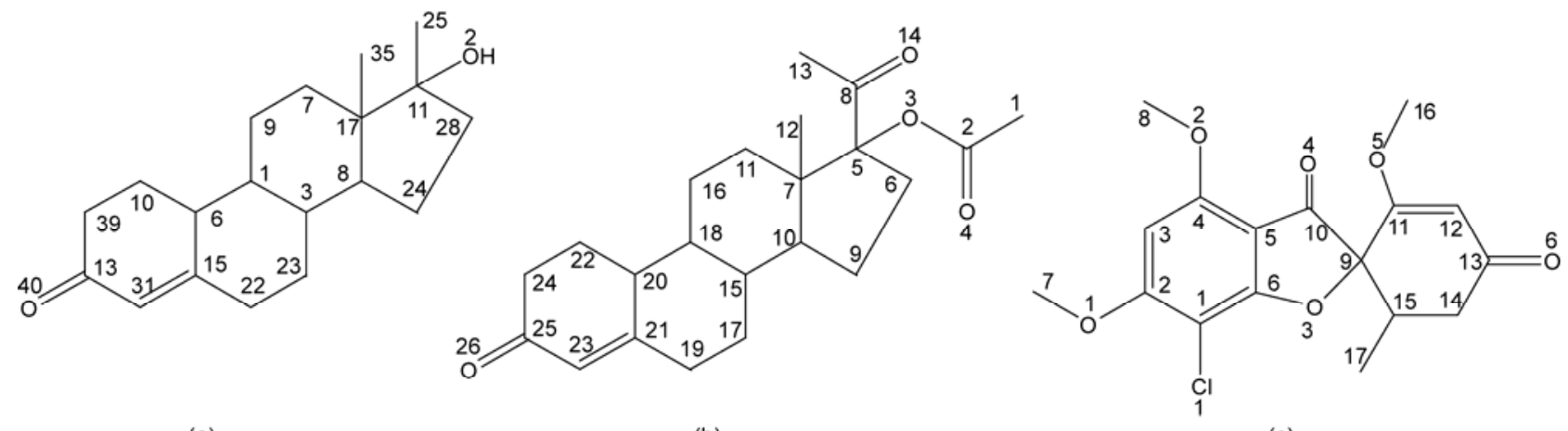

(a)

(b)

(c)

Figure 1 Molecular structures of normethisterone (a), gestonoronacetat (b), and griseofulvin (c).

The powder crystallographic data obtained from RR in MS and GSAS are compared with the single crystallographic data, which include the sequence and defined parameters, unit cell constants, and bond length and angle of molecules. The result shows that the crystal structure of small molecules based on different programs can be solved using laboratory XRPD facility.

\section{Experimental}

\subsection{Materials}

Normethisterone and gestonoronacetat were obtained from Zhejiang Xianju Yaoye Pharmaceutical Co., Ltd., China. Griseofulvin of more than $99 \%$ purity was purchased from Zhuhai Yuancheng Pharmaceutical \& Chemical Co., Ltd., China.

\subsection{Crystallization}

Normethisterone and gestonoronacetat were cultivated with 95\% ethanol solution and then statically placed at room temperature for $10 \mathrm{~d}$. The regular crystals were obtained for the SXRD, and the others were ground into powders for XRPD.

\subsection{XRPD}

The XRPD measurements were performed on an X'Pert PRO diffractometer (PANalytical Co., Ltd., Netherlands) equipped with an $\mathrm{X}$ 'celerator detection system using a $\mathrm{Cu}$ $\mathrm{K} \alpha$ radiation source $\left(\mathrm{K} \alpha_{1}=1.5406 \AA\right.$ and $\left.K \alpha_{2}=1.5444 \AA\right)$. The diffraction data were recorded at $298 \mathrm{~K}$ with a step size of $0.01313^{\circ}(2 \theta)$ within $5^{\circ}$ to $50^{\circ}$ in $2 \theta$ at $40 \mathrm{kV}$ and 40 $\mathrm{mA}$. The structural calculations were mostly conducted using the Reflex module in the MS 4.0 program (Accelrys Co., Ltd., USA) in the State Key Laboratory of Polymer Materials Engineering (Sichuan University, China). The application of GSAS was added for the part of RR.

\subsection{SXRD}

The SXRD data were collected on an Oxford diffraction
Xcalibur Nova with Mo K $\alpha$ radiation $\left(\lambda_{1}=0.071073 \mathrm{~nm}\right)$ at $293 \mathrm{~K}$ and $\theta$ range of $3.05^{\circ}$ to $28.77^{\circ}$. The single crystal structure of normethisterone and gestonoronacetat was determined by Olex2-1.1 program [12], which can interact with the SHELX program solved by direct approach, and refined with the SHELX-97 program.

\section{Results and discussion}

\subsection{Powder indexing}

The unit cell dimensions can be determined by indexing using X-Cell [13], DICVOL [14], ITO [15], and TREOR [16] programs and by analyzing the peak positions in the powder diffraction patterns [17]. The raw powder diffraction patterns were pretreated by calculating and subtracting the background, after which they were smoothened before stripping the $\mathrm{K} \alpha_{2}$ radiation. After automatic peak selection by the simple model, the unreasonable peaks were manually omitted. The X-Cell method was then used for indexing. The $\mathrm{X}$-Cell method can identify the correct indexing solution under the presence of impurity peaks. According to the value of the relative figure of merit, density, and distribution of the space group, the appropriate cell parameters were screened for the next stage called intensity extraction [18]. This procedure can be performed using Pawley [19] refinement from the powder refinement tool to fit an experimental powder pattern of an unknown crystal structure.

\subsection{Model construction and structure solution}

The molecular structures of normethisterone, gestonoronacetat, and griseofulvin were constructed and optimized using MS discover module. The Monte Carlo Simulated Annealing [20] search algorithm in the powder solve tool was used to adjust the conformation, position, and orientation of the trial model constantly to identify the global minima for the crystal structure parameters and to maximize the agreement between the calculated and measured diffraction data. After several attempts, the initial crystal structure was obtained. 


\subsection{RR}

The initial crystal structure obtained from the powder solve tool was refined by RR technique from the MS and GSAS packages. In RR from MS, the relative parameters were refined as variables. The background [21] coefficients with polynomial order 40 fitted better than the default order 20 with unusual variation for normethisterone. The diffraction profiles were modeled by the pseudo-Voigt function [22], and March-Dollase function [23] was chosen for preferred orientation refinement. In terms of structure parameters, every solo molecule was defined as a motion group to refine the bond lengths and angles. In addition, the atom positions were adjusted by the refinement of anisotropic temperature factors. Simultaneously, attempts were performed to refine the profile parameters prior to the structure parameters, but the value of $R_{\mathrm{wp}}$ was unstable, which may be attributed to refinement sequences and the intrinsic program design.

In the GSAS package, a Le Bail [24] fitting was conducted to apportion the intensity for overlapping reflections prior to the RR of the crystal structure model. The background was firstly edited manually using a type 1 Chebyshev polynomial with 14 terms, except for normethisterone that had 16. The parameter of the profile function type 3 was pseudo-Voigt with Finge-Cox-Jephcoat asymmetry, which needed low-angle data, so the histogram zero point correction was first released. The preferred orientation parameters acquired through the spherical harmonic formulation with order 10 and the cylindrical sample symmetry generally provided superior figures-of-merit compared with the March model [25]. After the peak shape was fitted well, the unit cell parameters and the background were refined. The values of $R_{\mathrm{wp}}$ were both less than $11 \%$.

Subsequently, each molecule was defined as a separate rigid body to retain a chemically realistic model. Translation, libration, and screw, which are terms that describe the rigid body thermal motions, should be turned off; otherwise, $R_{\text {wp }}$ would diverge. The atomic fractions and anisotropic temperature factors were slowly released by twos in the order of atomic number, and then refined together. The $R_{\mathrm{wp}}$ of the profile and structure parameter refinement were balanced, and all parameters formerly released were finally refined as the Rietveld model.

In the structure refinement from SXRD, different Fourier techniques can be adopted in conjunction with similar RR to complete the structural model. The molecular structures of normethisterone and gestonoronacetat were known, so all the atoms were easily identified from the electron density map, and the crystal structure was refined using full-matrix least-squares based on $F^{2}$ with the SHELXL program [26].

The ultimate crystallographic data are given in Table 1. The results of the single crystal determination were regarded as accurate values, and the relative error was used to analyze the differences between different Rietveld programs. The crystal system and the space group were consistent with those of the single crystal. We found that $a$ can be interchanged with $c$ in the $P 2{ }_{1} 2_{1} 2_{1}$ space group, which contains three sets of parallel diad screw axes parallel to each of the unit cell axes, because the method to transform the basis vectors and coordinates to those of the conventional cell was provided [27]. The symmetry for the $P 4_{1}$ space group arises from the fourfold rotation axis of the tetragonal point groups. The maximum relative errors of lengths $a, b$, and $c$ and volume were $0.18 \%, 0.18 \%, 0.22 \%$, and $0.39 \%$, respectively. In addition, the $R_{\mathrm{wp}}$ of MS was more than that of GSAS, which indicated that the profile fitting of GSAS was superior. These differences may have resulted from the separable refinement, different diffraction conditions, and different data processing algorithms.

The final three-dimensional (3-D) structures of SXRD are shown in Figure 2. The observed, and calculated, backgrounds

Table1 Relevant crystallographic data ${ }^{\text {a) }}$

\begin{tabular}{|c|c|c|c|c|c|c|c|c|c|}
\hline & & $a(\AA)$ & $b(\AA)$ & $c(\AA)$ & $\alpha\left(^{\circ}\right)$ & $v\left(\AA^{3}\right)$ & $Z$ & $R(\%)$ & Space group \\
\hline \multirow[t]{5}{*}{ Normethisterone } & SXRD & 9.5622 & 10.3953 & 33.7651 & 90 & 3356.33 & 8 & 5.99 & $P 2_{1} 2_{1} 2_{1}$ \\
\hline & MS & 33.8397 & 10.3960 & 9.5524 & 90 & 3360.51 & 8 & 8.85 & \\
\hline & GSAS & 33.7598 & 10.3885 & 9.5541 & 90 & 3350.76 & 8 & 6.88 & \\
\hline & $\mathrm{D}_{\mathrm{S \& M}}$ & $0.10 \%$ & $-0.01 \%$ & $-0.22 \%$ & 0 & $-0.12 \%$ & & & \\
\hline & $\mathrm{D}_{\mathrm{S \& G}}$ & $0.08 \%$ & $0.07 \%$ & $0.02 \%$ & 0 & $0.17 \%$ & & & \\
\hline \multirow[t]{4}{*}{ Gestonoronacetat } & SXRD & 6.8577 & 12.2243 & 23.2422 & 90 & 1948.38 & 4 & 4.38 & $P 2_{1} 2_{1} 2_{1}$ \\
\hline & GSAS & 23.2801 & 12.2253 & 6.8650 & 90 & 1953.83 & 4 & 9.58 & \\
\hline & $\mathrm{D}_{\mathrm{S \& M}}$ & $-0.09 \%$ & $-0.04 \%$ & $-0.12 \%$ & 0 & $-0.25 \%$ & & & \\
\hline & $\mathrm{D}_{\mathrm{S \& G}}$ & $-0.11 \%$ & $-0.01 \%$ & $-0.16 \%$ & 0 & $-0.28 \%$ & & & \\
\hline \multirow[t]{4}{*}{ Griseofulvin } & SXRD & 8.9692 & 8.9692 & 19.9515 & 90 & 1604.92 & 4 & 3.19 & $P 4_{1}$ \\
\hline & MS & 8.9853 & 8.9853 & 19.9553 & 90 & 1611.10 & 4 & 5.92 & \\
\hline & GSAS & 8.9728 & 8.9728 & 19.9225 & 90 & 1603.96 & 4 & 5.24 & \\
\hline & $\mathrm{D}_{\mathrm{S \& M}}$ & $-0.18 \%$ & $-0.18 \%$ & $-0.02 \%$ & 0 & $-0.39 \%$ & 0 & & \\
\hline
\end{tabular}

a) $R$ of SXRD is $R$-Factor, $R$ of MS and GSAS is $R_{\mathrm{wp}}$. $\mathrm{D}_{\mathrm{S} \& \mathrm{M}}$ and $\mathrm{D}_{\mathrm{S} \& \mathrm{G}}$ are the RR deviations from MS and GSAS, respectively, compared with the SXRD data. Space group represents a description of the crystal symmetry. $Z$ is the number of molecules in the unit cell. 
and the different patterns after RR using MS and GSAS packages are shown in Figure 3. The peak intensities and positions exhibited few differences between the experimental and calculated patterns. As shown in Figure 3(a) and (b), the background fitting from GSAS was more suitable than that from MS. GSAS allowed manual editing and fitting of the background, whereas MS can only set up the polynomial number of the fitting function.

The selected bond lengths and angles, including bonds in and out of the cycle are summarized in Table 2. Hydrogen atoms have very small scattering cross-sections for X-rays, so the positions of the hydrogen atoms from the simulation of an X-ray diffraction pattern during refinement may not be calculated. The range of bond lengths and angles were reasonable, and the deviations (except for hydrogen) were not more than $0.18 \%$. Thus, the deviation of GSAS was slightly larger. These differences in molecular structures may be attributed to the obscured diffraction intensities.

\section{Conclusions}

The accuracy of XRPD has been confirmed to a practical extent for organic compounds, especially for rigid molecular crystals based on our comparative analysis of the crystal structures of normethisterone, gestonoronacetat, and griseofulvin, as well as those we implemented before. The complexity of direct-space structure solution algorithms increases as the number of variables required to define the structural fragment increases. Thus, it is very critical that we must use all the chemical information and physical characteristics to simplify such variable space and accelerate the calculation.

Undoubtedly, the SXRD can be considered as the most powerful approach for the determination of structural infor-

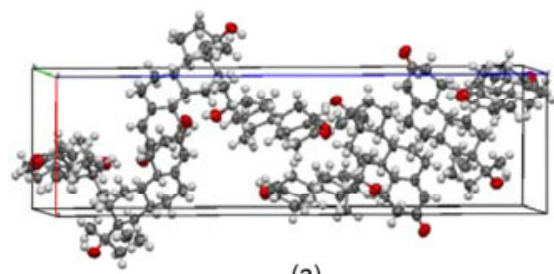

(a)

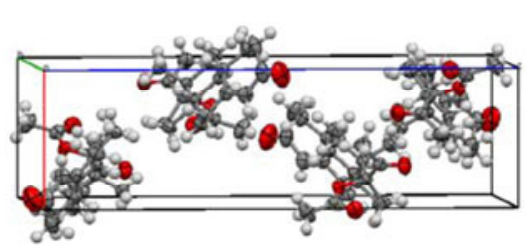

(b)

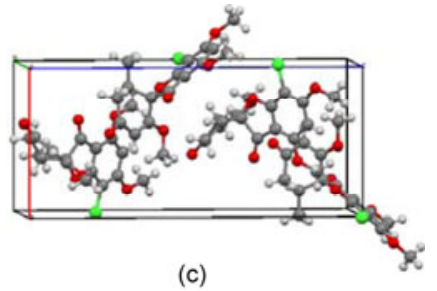

(c)

Figure 2 (Color online) Crystal cell packing diagrams of normethisterone (a), gestonoronacetat (b), and griseofulvin (c) by SXRD.
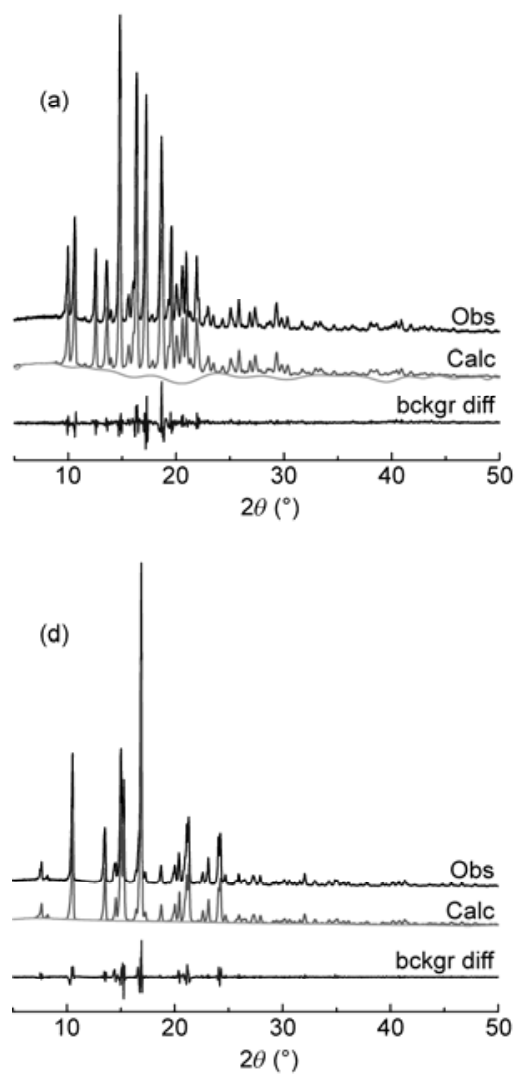
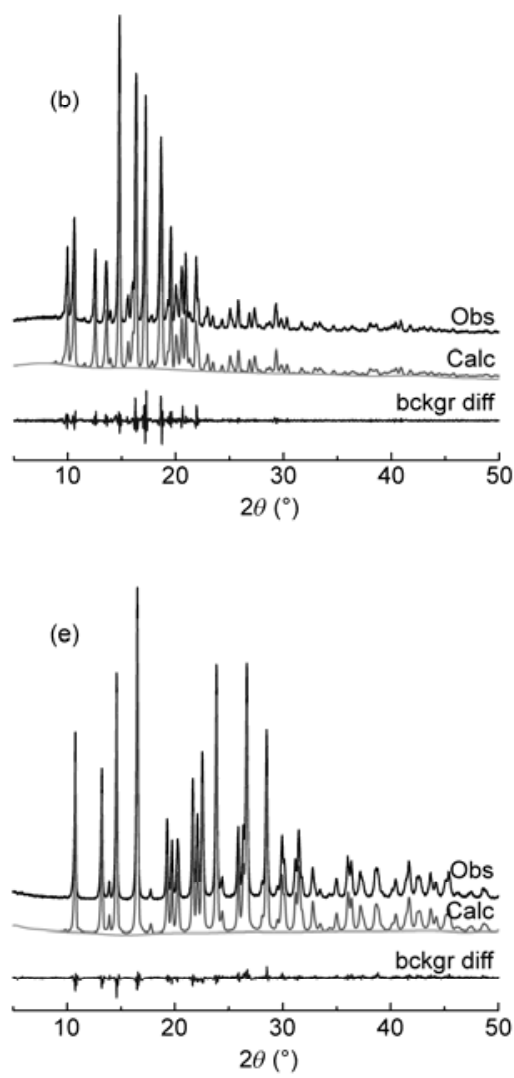
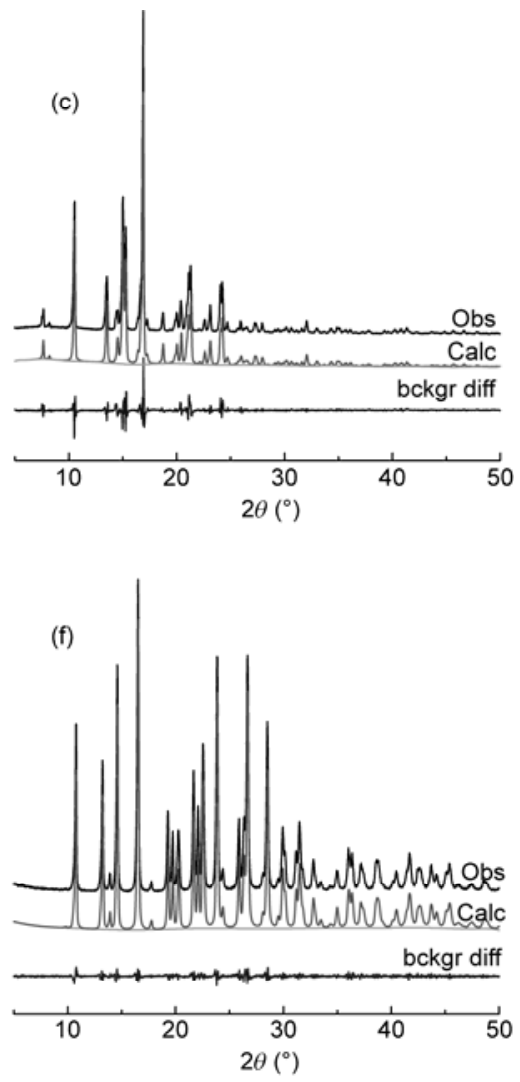

Figure 3 Powder diffraction patterns of normethisterone, gestonoronacetat, and griseofulvin after RR from MS (a), (c), (e) and GSAS (b), (d), (f). Obs: experimental pattern; Calc: the final calculated pattern after refinement; bckgr: the fitting background; diff: the pattern difference. 
Table 2 Selected bond lengths ( $\AA$ ), angles $\left({ }^{\circ}\right.$ ), and deviations (\%) from SXRD and XRPD

\begin{tabular}{|c|c|c|c|c|c|c|c|c|c|c|c|c|}
\hline & Length & SXRD & MS & GSAS & $\mathrm{D}_{\mathrm{D \& M}}$ & $\mathrm{D}_{\mathrm{D \& G}}$ & Angle & SXRD & MS & GSAS & $\mathrm{D}_{\mathrm{D \& M}}$ & $\mathrm{D}_{\mathrm{D \& G}}$ \\
\hline \multirow[t]{4}{*}{ Normethisterone } & C13-C39 & 1.4885 & 1.4885 & 1.4892 & 0.00 & -0.05 & C10-C1-C6 & 113.02 & 113.01 & 113.01 & 0.01 & 0.01 \\
\hline & C24-C28 & 1.5315 & 1.5310 & 1.5302 & 0.03 & 0.08 & $\mathrm{C} 17-\mathrm{C} 8-\mathrm{C} 24$ & 103.72 & 103.74 & 103.82 & -0.02 & -0.10 \\
\hline & $\mathrm{C} 11-\mathrm{C} 25$ & 1.5345 & 1.5343 & 1.5343 & 0.01 & 0.01 & $\mathrm{C} 28-\mathrm{C} 11-\mathrm{C} 25$ & 110.53 & 110.47 & 110.41 & 0.05 & 0.10 \\
\hline & C17-C35 & 1.5494 & 1.5488 & 1.5493 & 0.04 & 0.01 & C7-C17-C35 & 109.62 & 109.61 & 109.62 & 0.01 & 0.01 \\
\hline \multirow[t]{3}{*}{ Gestonoronacetat } & $\mathrm{C} 15-\mathrm{C} 18$ & 1.5363 & 1.5358 & 1.5353 & 0.03 & 0.06 & C20-C18-C16 & 112.62 & 112.64 & 112.82 & -0.02 & -0.18 \\
\hline & $\mathrm{C} 22-\mathrm{C} 24$ & 1.5183 & 1.5180 & 1.5193 & 0.02 & -0.06 & $\mathrm{C} 20-\mathrm{C} 22-\mathrm{C} 24$ & 111.72 & 111.69 & 111.72 & 0.03 & 0.00 \\
\hline & $\mathrm{C} 7-\mathrm{C} 12$ & 1.5383 & 1.5386 & 1.5383 & 0.02 & 0.00 & $\mathrm{C} 6-\mathrm{C} 5-\mathrm{C} 8$ & 114.12 & 114.06 & 114.01 & 0.05 & 0.09 \\
\hline \multirow[t]{4}{*}{ Griseofulvin } & $\mathrm{O} 3-\mathrm{C} 6$ & 1.3633 & 1.3627 & 1.3622 & 0.04 & 0.08 & C6-O3-C9 & 107.72 & 107.71 & 107.71 & 0.01 & 0.01 \\
\hline & $\mathrm{C} 2-\mathrm{C} 3$ & 1.3975 & 1.3974 & 1.3972 & 0.01 & 0.02 & $\mathrm{O} 3-\mathrm{C} 6-\mathrm{C} 1$ & 122.63 & 122.54 & 122.51 & 0.10 & 0.07 \\
\hline & $\mathrm{C} 1-\mathrm{C} 11$ & 1.7203 & 1.7196 & 1.7191 & 0.04 & 0.07 & C17-C9-C15 & 113.23 & 113.23 & 113.29 & -0.05 & 0.02 \\
\hline & $\mathrm{C} 11-\mathrm{O} 5$ & 1.3324 & 1.3326 & 1.3321 & -0.02 & 0.02 & O5-C11-C9 & 112.33 & 112.26 & 112.31 & 0.02 & 0.06 \\
\hline
\end{tabular}

mation at the atomic level when the single crystals of sufficient size and quality are available. When we can not obtain a suitable crystal sample, XRPD will be the most feasible alternative approach. As the diffraction data are distributed in 3-D space in the single crystal diffraction pattern, whereas they are "compressed" into one dimension in the powder diffraction.

The RR in MS and GSAS are in good agreement with that of SXRD. Furthermore, MS is operated more simply and consumes less computation time. The RRs for normethisterone, gestonoronacetat, and griseofulvin are about 77,105 , and $30 \mathrm{~min}$ in MS, and 567, 320, and $120 \mathrm{~min}$ in GSAS, respectively. Overall, MS is slightly better in the refinement of bond lengths and angles, whereas GSAS is more advantageous in profile fitting.

1 Harris K D M. Powder diffraction crystallography of molecular solids. Top Curr Chem, 2012, 315: 133-177

2 Smith D K, Gorter S J. Powder diffraction program information. 1990 program list. J Appl Crystallogr, 1991, 24: 369-402

3 Hu E P, Cheng Q, Guo L H, et al. Crystal structure determining of 7-ADCA based on X-ray powder diffraction. Chin Sci Bull, 2006, 51: 2421-2424

4 Lei X R, Yang J H, Lin X, et al. Crystal structure determination of Jatrorrhizine chloride. Chin Sci Bull, 2009, 54: 3244-3248

5 Guo P, Su Y H, Cheng Q, et al. Crystal structure determination of the $\beta$-cyclodextrin- $p$-aminobenzoic acid inclusion complex from powder X-ray diffraction data. Carbohydr Res, 2011, 346: 986-990

6 Young R A. The Rietveld Method. Oxford: International Union of Crystallography and Oxford University Press, 1993

7 Larson A C, Von Dreele R B. GSAS, Generalized structural analysis system, Document LAUR 86-748. Los Alamos National Laboratory, Los Alamos, NM, 1993

8 Rodriguez-Carvajal J. Fullprof: A program for Rietveld refinement and pattern matching analysis. In: Galy J, Louer D, eds. Satellite Meeting on Powder Diffraction of the 15th Congress of the IUCr. Toulouse: [sn], 1990. 127-128

9 TOPAS V3: General profile and structure analysis software for powder diffraction data. Bruker AXS, Karlsruhe, Germany, 2005

10 Rácz C P, Borodi G, Pop M M, et al. Structure of the inclusion complex of $\beta$-cyclodextrin with lipoic acid from laboratory powder diffraction data. Acta Crystallogr Sect B-Struct Sci, 2012, 68: 164-170
11 Pan Q Q, Guo P, Duan J, et al. Comparative crystal structure determination of griseofulvin: Powder X-ray diffraction versus singlecrystal X-ray diffraction. Chin Sci Bull, 2012, 57: 3867-3871

12 Dolomanov O V, Bourhis L J, Gildea R J, et al. OLEX2: A complete structure solution, refinement and analysis program. J Appl Crystallogr, 2009, 42: 339-341

13 Neumann M A. X-cell: A novel indexing algorithm for routine tasks and difficult cases. J Appl Crystallogr, 2003, 36: 356-365

14 Boultif A, Louër D. Indexing of powder diffraction patterns for lowsymmetry lattices by the successive dichotomy method. J Appl Crystallogr, 1991, 24: 987-993

15 Visser J W. A fully automatic program for finding the unit cell from powder data. J Appl Crystallogr, 1969, 2: 89-95

16 Werner P E, Eriksson L, Westdahl M. TREOR, a semi-exhaustive trial-and-error powder indexing program for all symmetries. J Appl Crystallogr, 1985, 18: 367-370

17 David W I F, Shankland K, McCusker L B, et al. Structure Determination from Powder Diffraction Data. Oxford: Oxford University Press, 2006

18 Shankland K, David W I F, Csoka T, et al. Structure solution of Ibuprofen from powder diffraction data by the application of a genetic algorithm combined with prior conformational analysis. Int J Pharm, 1998, 165: 117-126

19 Pawley G S. Unit-cell refinement from powder diffraction scans. J Appl Crystallogr, 1981, 14: 357-361

20 David V, Steven G L. A Monte Carlo simulated annealing approach to optimization over continuous variables. J Comput Phys, 1984, 56: 259-271

21 Brückner S. Estimation of the background in powder diffraction patterns through a robust smoothing procedure. J Appl Crystallogr, 2000, 33: 977-979

22 David W I F. Powder diffraction peak shapes. Parameterization of the pseudo-Voigt as a Voigt function. J Appl Crystallogr, 1986, 19: 63-64

23 Dollase W A. Correction of intensities for preferred orientation in powder diffractometry: Application of the March model. J Appl Crystallogr, 1986, 19: 267-272

24 Le Bail A, Duroy H, Fourquet J L. Ab-initio structure determination of $\mathrm{LiSbWO}_{6}$ by X-ray powder diffraction. Mater Res Bull, 1988, 23: $447-452$

25 Sitepu H, O'Connor B H, Li D. Comparative evaluation of the March and generalized spherical harmonic preferred orientation models using X-ray diffraction data for molybdite and calcite powders. J Appl Crystallogr, 2005, 38: 158-167

26 Sheldrick M G. SHELXL-97: Program for Crystal Structure Refinement. Gottingen, Germany: University of Gottingen, 1997

27 Wondratschek H, Müller U. The International Union of Crystallography Volume A1: Symmetry Relations between Space Groups. Netherlands: Springer, 2004

Open Access This article is distributed under the terms of the Creative Commons Attribution License which permits any use, distribution, and reproduction in any medium, provided the original author(s) and source are credited. 